\title{
Comparison of Two Sampling Methods for Quantifying Changes in Vegetation Composition Under Rangeland Development
}

\author{
Etienne Laliberté, ${ }^{1}$ David A. Norton, ${ }^{2}$ Jason M. Tylianakis, ${ }^{3}$ and David Scott ${ }^{4}$
}

Authors are ${ }^{1} \mathrm{PhD}$ candidate, School of Forestry, University of Canterbury, Private Bag 4800, Christchurch 8140, New Zealand; ${ }^{2}$ Associate Professor, School of Forestry, University of Canterbury, Private Bag 4800, Christchurch 8140, New Zealand; ${ }^{3}$ Senior Lecturer, School of Biological Sciences, University of Canterbury, Private Bag 4800, Christchurch 8140, New Zealand; and ${ }^{4}$ Researcher, 4 Murray Place, Lake Tekapo, New Zealand.

\begin{abstract}
Rapid vegetation sampling methods based on visual estimation are useful for monitoring changes in rangeland vegetation composition because large spatial and temporal scales are often involved and have limited sampling resources available. Here we compared two sampling methods in their ability to detect changes in vegetation composition following rangeland development: 1) species percent cover estimates within subplots (the percent cover [PC] method) and 2) rankings of relative biomass of the 10 most abundant species across the whole plot and the ratio of two of them (the visual ranking [VR] method). Both methods were applied on 30 experimental plots at year 26 of a long-term factorial trial of five soil fertility levels and three sheep grazing intensities. Multivariate statistical methods showed significant effects of experimental treatments (fertilizer level and sheep grazing intensity) and of vegetation sampling method (VR vs. PC) on vegetation composition. Importantly, we detected no significant interactions involving sampling method, indicating that the effect of sampling method was consistent across experimental treatments. Effects of fertilizer on vegetation composition were an order of magnitude greater than the effect of sampling method, whereas the latter was twice as important as the effect of grazing. Results were robust to differential weights given to relative abundances vs. compositional changes. Differences between methods were primarily driven by the PC method giving lower abundance estimates of one species, lupin (a hybrid of Lupinus polyphyllus Lindl.), relative to the VR method. Our results support the use of the VR method as a rapid yet powerful method for monitoring changes in vegetation composition under rangeland development.
\end{abstract}

\section{Resumen}

Los métodos de muestreo rápido de vegetación son útiles para señalar cambios en la composición vegetal de pastizales, debido a las grandes escalas espaciales y temporales frecuentemente involucradas y los limitados recursos de muestreo disponibles. Aqui, comparamos dos métodos de muestreo respecto a su capacidad de detectar cambios en la composicion vegetal en parcelas con distintas intensidades de pastoreo: 1) porcentaje de cobertura de especies estimado en subparcelas (método de porcentaje de cobertura [PC]), y 2) clasificación visual ("Visual Ranking" [VR]), en el cual las diez especies de mayor abundancia por parcela se clasifican visualmente en función de la biomasa aérea. Ambos métodos fueron aplicados en 30 parcelas experimentales después de 26 años de aplicación factorial de niveles diferenciales de fertilizacion del suelo y diferentes intensidades de pastoreo. Usando estadística multivariada, encontramos que tanto los tratamientos experimentales (nivel de fertilización e intensidad de pastoreo de ovejas) como el método de muestreo de la vegetación (VR vs. PC) tienen efectos significativos en la composición vegetal. Más importante aun, no observamos ninguna interacción significativa al involucrar el método de muestreo, lo que indica que el efecto del método de toma de muestras fue consistente a través de los tratamientos experimentales. Los efectos de los fertilizantes en la composición vegetal fueron un orden de magnitud mayor que el efecto del método de muestreo, mientras que éste fue dos veces más importante que el efecto del pastoreo. Los resultados fueron robustos a pesos diferenciales de las abundancias relativas frente a los cambios de composición. Las diferencias entre métodos fueron principalmente causadas por el método de PC, subestimando la abundancia de una especie, altramuz (híbrido de Lupinus polyphyllus Lindl.), en relación al método VR. Nuestros resultados apoyan el uso del método VR como un método rápido y potente para el monitoreo de cambios en la composición vegetal de pastizales en fase de desarrollo.

Key Words: community composition, monitoring, rangeland assessment, vegetation sampling, visual ranking

\section{INTRODUCTION}

Funding for this research was made possible by the Miss E. L. Hellaby Indigenous Grassland Research Trust. During the writing of this manuscript, E. Laliberté was supported by scholarships from the University of Canterbury, the Fonds québécois de recherche sur la nature et les technologies (FQRNT), and Education New Zealand. This project is endorsed by the Global Land Project (http://www.globallandproject.org).

Correspondence: Etienne Laliberté, School of Forestry, University of Canterbury, Private Bag 4800, Christchurch 8140, New Zealand. Email: etiennelaliberte@gmail.com

Manuscript received 18 October 2009; manuscript accepted 24 May 2010.
A wide array of different vegetation sampling methods are available for quantifying species abundance in plant communities (Mueller-Dombois and Ellenberg 2003). Methods are generally judged on precision (how well does the sample represent the "true" value), repeatability among different observers, and efficiency (the amount of resources spent, particularly time, per unit information gained; Symstad et al. 
2008). With regard to long-term rangeland monitoring, efficiency is often a primary practical concern because of the large spatial and temporal scales involved and the often-limited funding available (Stohlgren et al. 1998). As a result, rapid and cost-effective methods for monitoring rangeland vegetation have been proposed (e.g., Friedel and Chewings 1988; Meentemeyer and Moody 2000).

The listing or ranking of species in their descending order of abundance is commonly used in describing vegetation composition in a sample unit and has been formalized in some sampling methods. In the dry-weight-rank technique ('t Mannetje and Haydock 1963), this is done by visually ranking the first three most abundant species in subplot samples and assuming these are generally in fixed proportions of biomass, based on extensive earlier clip quadrat studies. The present work used visual ranking of up to ten species in a sample unit for their contribution to standing biomass (Scott 1989), which we refer to as the "visual ranking" (VR) method. Compared to the dry-weight-rank technique, the VR method shifts the assumption from the constancy of the species proportions to a $\mathrm{log} / \mathrm{linear}$ relationship whose gradient can be determined by estimating the abundance ratio between two species (generally between the fifth- and first-ranked species; Scott 1989). The rationale behind such visual ranking methods is that much information on a given plant community can be obtained by simply knowing the relative order of importance for the first few dominant species ('t Mannetje and Haydock 1963; Scott 1989). The VR method has since been used in different applications (Linklater and Cameron 2000, 2009; Scott 2001, 2007). This method was shown to be little influenced by the observer (Scott 1989), but has not yet been compared to other vegetation sampling methods.

The objective of the present study was to compare the VR method with a more field-intensive vegetation sampling approach using several randomly located subquadrats per plot, from which percent cover of all vascular plant species was assessed visually (henceforth referred to as the "percent cover method" [PC]; Mueller-Dombois and Ellenberg 2003). However, because the VR method estimates only the ranks of the most abundant species in a sample unit, our objective was not to compare the ability of each method to detect rare species, as other authors have done in comparisons of other sampling methods (West and Reese 1991; Stohlgren et al. 1998; Prosser et al. 2003; Symstad et al. 2008; GodínezAlvarez et al. 2009). Instead, our objective was to compare the relative ability of the VR and PC methods to detect changes in vegetation composition following contrasting rangeland development strategies (fertilization, irrigation, and grazing intensity). We defined vegetation composition as the relative abundances (i.e., which species are present, and in what proportion) of the most abundant plant species within a given community. If the differences in vegetation composition identified by the VR and PC methods are consistent across development treatments, then either method could be used for monitoring in this type of situation. Conversely, if the methods differ in their ability to discriminate compositional changes caused by treatments (i.e., if there is a significant treatment $X$ method interaction), then the more sensitive sampling method may be preferred.

\section{METHODS}

\section{Study Area}

The study was conducted on the AgResearch Mount John trial site, west of Lake Tekapo in the Mackenzie Basin of New Zealand's South Island (lat $43^{\circ} 59^{\prime} \mathrm{S}$, long $170^{\circ} 27^{\prime} \mathrm{E}, 820 \mathrm{~m}$ above sea level). The climate is semicontinental with an average of 1772 degree-days above $5^{\circ} \mathrm{C}$ and a mean annual temperature of $8.7^{\circ} \mathrm{C}$, with $14.9^{\circ} \mathrm{C}$ in January (warmest) and $1.7^{\circ} \mathrm{C}$ in July (coldest). Mean annual rainfall is $601 \mathrm{~mm}$ and is uniformly distributed throughout the year. The average annual moisture deficit is $445 \mathrm{~mm}$. Prevailing winds are from the northwest and are often strong. Soils are Humose, Orthic Brown (Hewitt 1998), between $45 \mathrm{~cm}$ and $90 \mathrm{~cm}$ deep, and were developed from greywacke and argillite rock till material subsequent to the retreat of the Tekapo glacier about $13000 \mathrm{yr}$ ago. The dominant vegetation type prior to human settlement in the area was likely to have been short-tussock grassland with a variable woody component, probably near the tall tussock (Chionochloa sp.)-short tussock (Festuca novae-zelandiae Hack. Cockayne) transition (McGlone 2001). Early human occupation started around 700-800 yr ago and has been linked with increased fire frequency (McGlone 2001). Extensive grazing by sheep was introduced to the area in the 1840-1850s and remains the most important land use today.

\section{Experimental Design}

A long-term (1982 to present) rangeland improvement experiment known as the "Graze $\times$ fert" trial was used for the present study (Scott 1999). The original aim of this trial was to identify the realized niches of different pasture species under contrasting development inputs and grazing intensities (Scott 2001). The experimental design is described in detail by Scott (1999) and is summarized here. In 1982, a mixture of 25 grass and legume pasture species was oversown using a rotary hoe drill within a 3ha area of depleted fescue tussock (F. novae-zelandiae Hack. Cockayne) grassland dominated by the exotic mouse-ear hawkweed (Hieracium pilosella L.), a vegetation type that is representative of large areas of New Zealand rangelands (Scott 1985; Hunter 1991). The "Graze $\times$ fert" trial was established within the oversown area, following a split-plot design consisting of two spatial replications (blocks), each split into five plots (i.e., "whole plots" according to the split-plot terminology) receiving one of the following five nominal fertilizer treatments: $0 \mathrm{~kg} \cdot \mathrm{ha}^{-1} \cdot \mathrm{yr}^{-1}, 50 \mathrm{~kg} \cdot \mathrm{ha}^{-1} \cdot \mathrm{yr}^{-1}$, $100 \mathrm{~kg} \cdot \mathrm{ha}^{-1} \cdot \mathrm{yr}^{-1}, 250 \mathrm{~kg} \cdot \mathrm{ha}^{-1} \cdot \mathrm{yr}^{-1}$, and $500 \mathrm{~kg} \cdot \mathrm{ha}^{-1} \cdot \mathrm{yr}^{-1}$ of sulfur fortified superphosphate. The plots receiving $500 \mathrm{~kg} \cdot \mathrm{ha}^{-1} \cdot \mathrm{yr}^{-1}$ of superphosphate were also irrigated fortnightly from November to May of each year. Fertilizer was applied each year for the first $20 \mathrm{yr}$ of the experiment.

Each plot was further split into six individually fenced $8 \times 50 \mathrm{~m}$ subplots corresponding to a two-way factorial design involving grazing intensity (lax, moderate, and hard) and stocking type (mob vs. sustained). Grazing intensity levels (lax, moderate, and hard) corresponded to a 1:2:4 sheep-grazing days ratio in years 2-4 of the experiment and 2:3:4 in subsequent years. Plots were grazed in groups of three (lax, moderate, and hard grazing), and sheep numbers were adjusted based on available feed-on-offer of the moderate grazing 
subplot. The duration of grazing for all three subplots was based on residual bulk of the moderate grazing subplot. In mob grazing subplots, a larger number of sheep (with actual numbers depending on available feed-on-offer of the moderate subplot) were introduced to subplots for 3-4 d, while sustained grazing subplots received fewer sheep for a longer period (e.g., several weeks). Only subplots corresponding to the mob stocking type were considered in the present study.

For the present study, an additional factor, vegetation sampling method (two levels: VR vs. PC), was added to this experimental design. The outputs from the two methods were paired per subplot. Because sampling method was nested within subplots, this effectively transformed the experiment into a split-split-plot design for the purpose of statistical analyses.

\section{Vegetation Sampling}

For the VR method, the sample unit was the entire subplot in which the 10 most abundant vascular plant species were visually ranked according to standing biomass (Scott 1989). The ratio of abundance between the fifth- and first-ranked species (henceforth called the "5:1 ratio") was also estimated (Scott 1989). Once all 30 subplots were sampled, the whole procedure was repeated two additional times, but only for the first five most abundant species in each subplot. In order to derive species relative abundances from ranks for each of the three rounds, we followed Scott's (1989) suggestion to use the 5:1 ratio to yield the geometric sequence

$$
a, a r^{1}, a r^{2}, a r^{3}, a r^{4}, a r^{5}, \ldots, a r^{n-1},
$$

where $a=r / \sum_{i=0}^{n-1} r^{i}, r$ (the common ratio) is equal to $\sqrt[4]{5: 1 \text { ratio, }}$ and $n=10$ species. The $5: 1$ ratio is used to determine the gradient of the linear relationship between $\log$ (abundance) and rank, thereby enabling estimation of the relative abundances of all species.

For statistical analyses, results of the three rounds were averaged, and only the first five most abundant species per subplot were kept. The first five most abundant species in each subplot together accounted for $79.7-99.7 \%$ of abundance, such that changes in vegetation composition should be well reflected by considering the five most abundant species only.

For the PC method, $201 \times 1 \mathrm{~m}$ quadrats (sample units) were randomly positioned along two longitudinal transects in each subplot. Transects were $3 \mathrm{~m}$ apart from each other and $2 \mathrm{~m}$ from the closest fence to avoid edge effects. Cover (i.e., vertical projection of canopy, including living and nonliving components) of all vascular plant species present in each $1 \times 1 \mathrm{~m}$ quadrat was recorded using a seven-point semiquantitative scale $(1, \leq 0.1 \% ; 2,0.1-0.9 \% ; 3,1-5 \% ; 4,5-25 \% ; 5,26-$ $50 \% ; 6,51-75 \% ; 7,76-100 \%)$. Mean percent cover per species per subplot was calculated by taking the median of the cover class for each species in all 20 quadrats, then averaging across these quadrats. Because percent cover is estimated individually for each species, and because canopy projections of different species can overlap, mean percent cover could exceed $100 \%$. Species present within the whole subplot but in none of the individual $201 \times 1 \mathrm{~m}$ quadrats were assigned the lowest possible cover value (i.e., the median of cover class 1 , divided by 20). Percent cover data per subplot were transformed to relative abundances by dividing the percent cover of each species by the sum of percent cover values for all species present. As with the VR method, only the first five most abundant species per subplot were kept for analyses. In each subplot, these first five most abundant species together accounted for $81.9-99.6 \%$ of abundance.

For both methods, sampling was undertaken by the same observer (E. L.) in year 26 of the experiment (early November 2008). Methods were followed independently and not simultaneously, such that all subplots were first sampled using the PC method before moving on to the VR method. Sampling all 30 subplots with the PC method took three consecutive days, while the VR method was done in one afternoon (about one hour per round, three hours total). Temporal separation of sampling methods (and the fact that the PC field data were deliberately not consulted prior to VR) minimized the chances of the results of one method influencing the other.

\section{Statistical Analyses}

To see whether changes in vegetation composition should be well reflected by considering the five most abundant species only, we used data from the PC method (which included all plant species) and compared the first 20 principal coordinates of Modified-Gower distance matrices (base 10; Anderson et al. 2006) computed from the full data set (all species) and the reduced data set (only the five most abundant species per subplot) through a Procrustes test (Peres-Neto and Jackson 2001). These first 20 principal coordinates represented $100 \%$ and $99.82 \%$ of the variation of the reduced and full data sets, respectively. The Procrustes test was run using 999 permutations with the "protest" function of the "vegan" package (Oksanen et al. 2010). We found a strong and highly significant Procrustes correlation between the two multivariate data sets $\left(r_{\text {Proc }}=0.850 ; P=0.001\right)$, suggesting that only considering the first five most abundant species should reflect well changes in vegetation composition.

We computed the Pearson correlation coefficient $r$ between the relative abundance data (ranging from 0 to 100) collected with the VR method and the data collected with the PC method, after $\log (x+1)$ transformation. We also used major axis regression (with no intercept) on the $\log (x+1)$ transformed data and tested whether the slope differed from 1 (Warton et al. 2006). For the eight most abundant plant species across all treatments, we used biplots for visual comparisons of the observed data against the 1:1 line.

The effects of fertilizer, grazing intensity, and vegetation sampling method and their interactions on vegetation composition were tested using permutational distance-based multivariate analysis of variance (ANOVA; McArdle and Anderson 2001). This method is superior to traditional approaches (e.g., MANOVA) for analyzing changes in composition because it can be based on any ecologically meaningful distance metric, and not only the Euclidean distance (McArdle and Anderson 2001). Moreover, $P$ values are obtained using permutations of the raw data or the residuals, such that no assumptions are made about multivariate normality. This is important because community data rarely meet these assumptions due to heavily 
positively skewed distributions and an over-abundance of zeros (Legendre and Legendre 1998). Experimental treatments (fertilizer, grazing intensity, and sampling method) were treated as fixed factors, whereas block, whole plot, and subplot were treated as random factors.

We conducted three sets of analyses, each focusing on a different distance/dissimilarity measure. This is particularly important for distance-based analyses because the distance measure can have a strong influence on the results, and because it is useful to explicitly specify the relative importance given to changes in species relative abundances vs. changes in presenceabsence in the analysis (Anderson et al. 2006). To take this into account, the first test used presence-absence data with the Jaccard dissimilarity (Legendre and Legendre 1998). The second test used the Modified-Gower distance with base 10 (MG10; Anderson et al. 2006). This distance measure considers an order-of-magnitude change in abundance (e.g., from 1 to 10) equal to a change in presence-absence (i.e., from 0 to 1 ; Anderson et al. 2006). The third analysis used the same distance measure but with base 2 (MG2), effectively putting the same weight to a doubling in abundance (e.g., from 1 to 2 ) as a change in presence-absence (Anderson et al. 2006).

Error structure followed a split-split-plot design, with whole plots acting as error for testing fertilizer effects, subplots acting as error for testing grazing effect and its interaction with fertilizer, and "sub-subplots" ( 30 subplots $\times 2$ methods $=60$ "sub-suplots," following the split-split-plot terminology) acting as error for testing the effect of vegetation sampling method and its interactions with fertilizer and grazing. As with any split-plot design, such a model has lesser power for detecting treatment effects at the whole plot level (i.e., fertilizer effects), but power progressively increases at the lower levels (i.e., grazing intensity and vegetation sampling method effects; Gotelli and Ellison 2004). Underlying assumptions of this split-split-plot model are that all interactions involving blocks, whole plots, or subplots are negligible (Gotelli and Ellison 2004).

In order to visualize patterns in vegetation composition under the different experimental treatments, we used nonmetric multidimensional scaling (MDS; Shepard 1962; Kruskal 1964) as an ordination method. MDS returns a two-dimensional biplot that best represents the distance of individual samples (i.e., subplots) in multivariate space. We also used components of variation $(\mathrm{CoV})$ to compare the relative importance of treatments on vegetation composition (Anderson et al. 2008). For fixed factors these represent the sum of squared fixed effects divided by the appropriate degrees of freedom and can be directly compared to each other to estimate the relative importance of treatments from any design, including split-plot designs (Anderson et al. 2008).

We used $1 \mathrm{df}$ contrasts for significant terms to further partition significant terms according to a priori hypotheses generated from visual exploration of the MDS plot. The wholeplot analyses used 9999 permutations of the raw data, while 9999 permutations of the residuals under a reduced model were used for the other analyses. We used Monte Carlo asymptotic $P$ values when there was a low number of possible unique permutations (Anderson and Robinson 2003).

To complement the distance-based multivariate ANOVA tests, we used canonical analysis of principal coordinates (CAP;
Anderson and Willis 2003) to visualize and interpret significant differences between treatment levels obtained from permutational distance-based multivariate ANOVA when these were not obvious from the MDS biplot. The purpose of CAP is to find axes in multivariate space that are best at discriminating between a priori groups (Anderson and Willis 2003). All analyses were conducted in the PRIMER v6/PERMANOVA+ environment (Clarke and Gorley 2006; Anderson et al. 2008).

\section{RESULTS}

\section{Sampling Method}

The species relative abundances collected from both methods were positively associated, though this relationship was not strong $(r=0.491$ after $\log [x+1]$ transformation, $P<0.0001$; Fig. 1). The slope of the major axis regression line did not differ significantly from $1\left(b_{\mathrm{MA}}=0.997\right.$; Fig. 1$)$. The VR method gave greater abundance estimates for lupin (a hybrid of Lupinus polyphyllus Lindl.), fescue tussock, and to a lesser degree tall oat-grass (Arrhenatherum elatius L.), relative to the PC method (Fig. 1). It gave slightly lower abundance estimates for mouse-ear hawkweed and zig-zag clover (Trifolium ambiguum M. Bieb.) at medium abundance levels (i.e., in the $20-40 \%$ range; Fig. 1$)$.

Vegetation sampling method, fertilizer, and grazing intensity all had significant $(P \leq 0.05)$ effects on vegetation composition when the latter was expressed using the MG10 distance (Table 1). Importantly, there were no significant interactions involving vegetation sampling method (Table 1), indicating that effects of vegetation sampling method on the observed vegetation composition were consistent in size and direction across fertilizer and grazing treatments.

The CoV showed that fertilizer had by far the greatest effect on vegetation composition $(\mathrm{CoV}=0.432)$, its effect being an order of magnitude greater than sampling method $(\mathrm{CoV}=0.044)$, with the latter accounting for almost twice as much variation in vegetation composition as grazing intensity $(\mathrm{CoV}=0.028$; Table 1$)$.

The differences in vegetation composition between sampling methods identified from the main test (Table 1) were not obvious from the MDS plot (Fig. 2a). Therefore, we used CAP (Anderson and Willis 2003) to find the canonical axis that best discriminated subplots according to sampling method. Of all plant species, lupin had the greatest Pearson correlation with this CAP axis $(r=-0.293)$, indicating that it was more abundant in subplots sampled under the VR method. This reinforced our previous finding that the VR method gave higher estimates of the abundance of lupin relative to the PC method (Fig. 1).

\section{Treatment Effects}

The strong fertilizer effect could be readily identified from the MDS plot (Fig. 2a), with nonfertilized subplots (black symbols) being clearly separated from fertilized ones in ordination space. There was also an apparent distinction of highly fertilized/irrigated suplots (white symbols) from those of other fertilizer levels, while subplots receiving $50 \mathrm{~kg} \cdot \mathrm{ha}^{-1} \cdot \mathrm{yr}^{-1}$, $100 \mathrm{~kg} \cdot \mathrm{ha}^{-1} \cdot \mathrm{yr}^{-1}$, or $250 \mathrm{~kg} \cdot \mathrm{ha}^{-1} \cdot \mathrm{yr}^{-1}$ of superphosphate did not appear to differ from each other in terms of vegetation 
all species

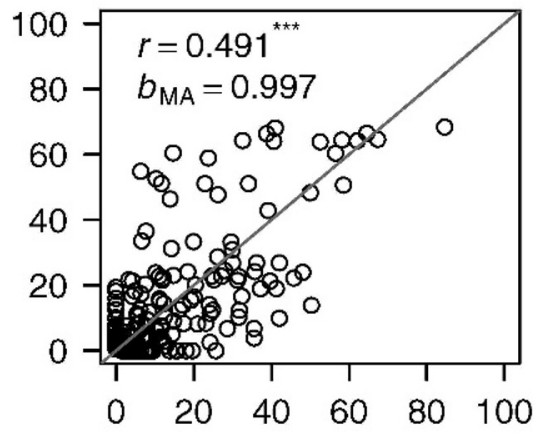

zig-zag clover

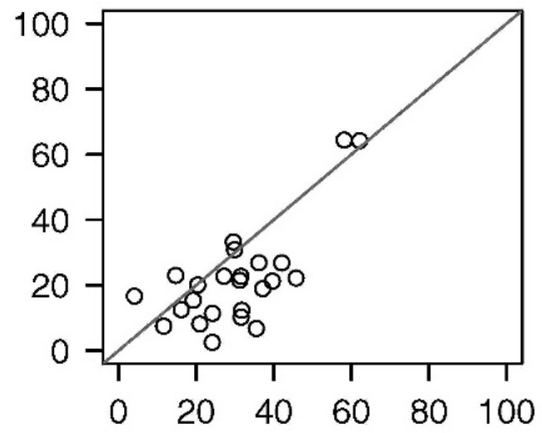

Chewing fescue

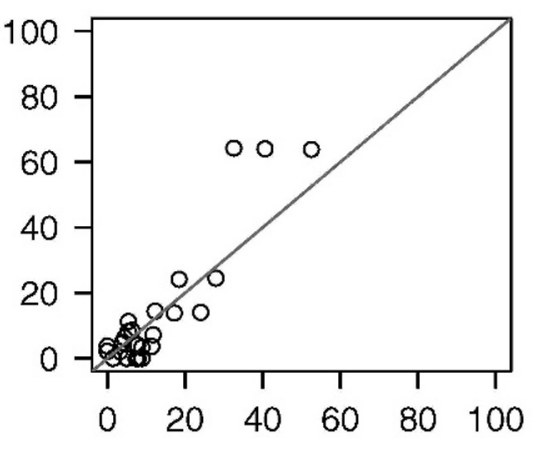

Iupin

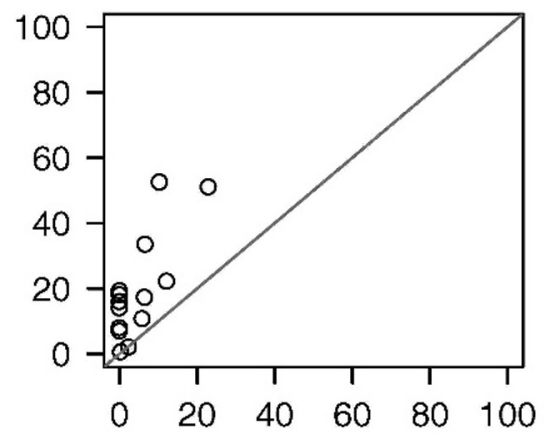

tall oat-grass

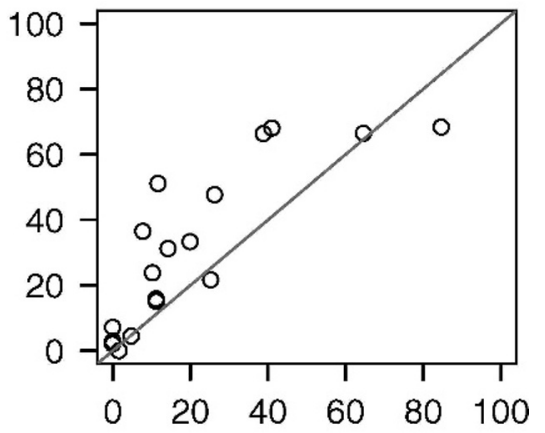

Kentucky bluegrass

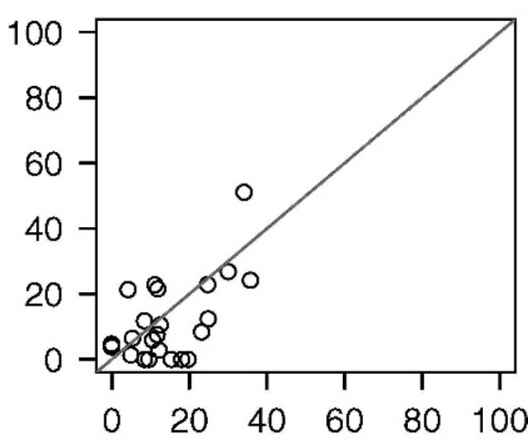

fescue tussock

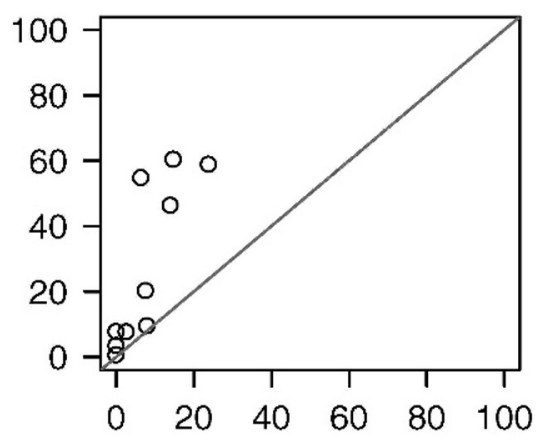

Relative abundances PC (\%)

\section{cheatgrass}

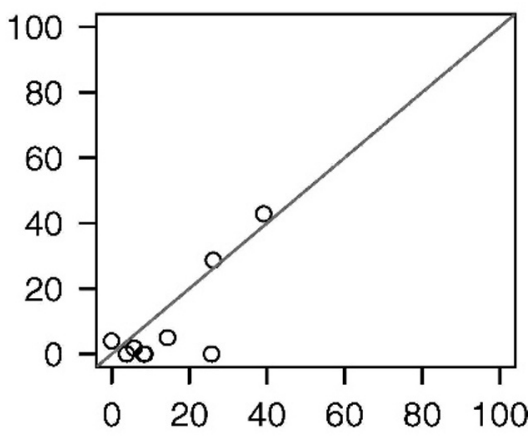

Figure 1. Biplots showing the relationships between the visual ranking (VR) method and the percent cover (PC) method. This was done for all species (top left graph) and individually for the eight most abundant plant species across all treatments. Graphs for individual species are shown in decreasing order of overall abundance, starting from the top row and moving right. Gray lines indicate a 1:1 relationship. Data from the top-left graph were $\log (x+1)$ transformed to compute the Pearson correlation coefficient $r$ and the major axis regression slope $b_{\mathrm{MA}}$ (no intercept). cheatgrass $=$ Bromus tectorum L.

composition. A priori contrasts (Table 1) revealed significant differences in vegetation composition between the nonfertilized subplots and the other ones $(P=0.003)$, but not of highly fertilized/irrigated subplots from the others $(P=0.100)$. Again, similar results were obtained using the other two distance measures (see Tables S1 and S2, available at http://dx.doi.org/ 10.2111/REM-D-09-00156.st1 and http://dx.doi.org/10.2111/ REM-D-09-00156.st2).

Species showing a Pearson correlation $r>0.5$ with any of the two MDS axes were added as a vector overlay on the MDS plot
(Fig. 2b); we used this cutoff for improving visual clarity, by eliminating species showing weaker relationships with the MDS axes. This indicated that along the first MDS axis, zerofertilizer subplots were characterized by a greater abundance of mouse-ear hawkweed, fescue tussock, blue tussock (Poa colensoi Hook.f.), and Pyrranthera exigua (Kirk) Zotov, while fertilized subplots contained a greater abundance of zig-zag clover and Kentucky bluegrass (Poa pratensis L.; Fig. 2). A notable feature of the second MDS axis was that highly fertilized/irrigated subplots were characterized by a greater 
Table 1. Results of permutational distance-based multivariate ANOVA, using the Modified Gower distance base 10 (Anderson et al. 2006 ). Error structure followed a split-split-plot design. Fertilizer (Fert) $\times$ Grazing intensity (Graz) $\times$ Sampling method interaction was excluded from the model because it had a negative component of variation (CoV), as recommended by Anderson et al. (2008). $P$ values in bold indicate significant differences at $\alpha=0.05$ (9999 permutations).

\begin{tabular}{|c|c|c|c|c|c|c|c|}
\hline Source & Contrasts & $d f$ & $\mathrm{SS}^{1}$ & $\mathrm{MS}^{1}$ & Pseudo- $F$ & $P^{2}$ & $\mathrm{CoV}^{3}$ \\
\hline Block & & 1 & 2.473 & 0.412 & 1.301 & 0.303 & 0.019 \\
\hline \multirow[t]{4}{*}{ Fert } & & 4 & 28.340 & 1.181 & 3.726 & 0.014 & 0.432 \\
\hline & 0 vs. other & 1 & 17.559 & 2.927 & 6.684 & 0.003 & 0.778 \\
\hline & 0 vs. 500 & 1 & 14.758 & 2.460 & 12.109 & 0.085 & 1.128 \\
\hline & 500 vs. other & 1 & 8.708 & 1.451 & 2.238 & 0.100 & 0.251 \\
\hline Whole plot error & & 4 & 7.607 & 0.317 & - & - & 0.317 \\
\hline Whole plot total & & 9 & 38.420 & - & - & - & - \\
\hline \multirow[t]{3}{*}{ Graz } & & 2 & 2.282 & 0.571 & 1.974 & 0.047 & 0.028 \\
\hline & Low vs. other & 1 & 1.739 & 0.870 & 2.667 & 0.019 & 0.041 \\
\hline & Low vs. high & 1 & 1.773 & 0.886 & 3.595 & 0.029 & 0.064 \\
\hline Fert $\times$ graz & & 8 & 7.104 & 0.444 & 1.536 & 0.042 & 0.078 \\
\hline Subplot error & & 10 & 5.780 & 0.289 & - & - & 0.289 \\
\hline Subplot total & & 29 & 15.166 & - & - & - & - \\
\hline Method & & 1 & 1.609 & 1.609 & 5.765 & 0.000 & 0.044 \\
\hline Fert $\times$ method & & 4 & 1.263 & 0.316 & 1.131 & 0.301 & 0.006 \\
\hline Graz $\times$ method & & 2 & 0.792 & 0.396 & 1.420 & 0.156 & 0.012 \\
\hline Sub-subplot error & & 23 & 6.420 & 0.279 & - & - & 0.279 \\
\hline Total & & 59 & 63.670 & - & - & - & - \\
\hline
\end{tabular}

${ }^{1} \mathrm{SS}$ indicates sum of squares; MS, mean square.

${ }^{2}$ Monte Carlo $P$ values were used because of low number of unique permutations; see Anderson and Robinson (2003) for details.

${ }^{3} \mathrm{CoV}=$ components of variation, see Anderson et al. (2008) for details.

abundance of Chewing's fescue (Festuca rubra subsp. commutata Gaudin), while they contained little lupin relative to other fertilized subplots (Fig. 2).

There was a significant fertilizer $\times$ grazing intensity interaction $(P=0.042$; Table 1$)$, suggesting that effects of grazing on vegetation composition were not consistent across fertilizer levels. However, post hoc pairwise comparisons did not indicate significant differences due to grazing among the different fertilizer levels (results not shown), possibly because of low power. Patterns in the MDS plot (Fig. 2a) suggested that this significant interaction may result from grazing showing little effect on vegetation composition in highly fertilized/irrigated subplots relative to other fertilizer levels. In particular, among subplots receiving $100 \mathrm{~kg} \cdot \mathrm{ha}^{-1} \cdot \mathrm{yr}^{-1}$ of superphosphate, those under hard grazing (Fig. 2a; triangles) appeared to occupy a distinct location in ordination space compared with those under moderate (Fig. 2a; squares) or lax grazing (Fig. 2a; circles).

The main grazing intensity effect was not obvious from the MDS plot (Fig. 2a). Therefore, we used CAP to find the linear combinations of principal coordinates that best discriminated subplots under different grazing intensities. The resulting CAP biplot (Fig. 3a) showed that differences were between the laxgrazing treatment and the other two grazing levels, which was confirmed by a significant a priori contrast (Table 1). A vector overlay of all species showing a Pearson correlation $r>0.3$ was added to the CAP biplot, but no species showed particularly strong associations with any of the MDS axes, which was reflected by the short length of all vectors (Fig. 3b). The $r>0.3$ cutoff was chosen here because of relatively weak associations of individual species with the CAP axes. Nevertheless, there was a tendency (as seen along CAP axis 1) for lax-grazing subplots to have greater abundance of tall oat-grass, timothy (Phleum pratense L.), and Chewing's fescue, while moderately and highly grazed ones had a greater abundance of Kentucky bluegrass and zig-zag clover (Fig. 3).

Very similar results were obtained when only presenceabsence data (using the Jaccard dissimilarity) were considered (Table S1) as well as when vegetation composition was expressed using the MG2 distance (Table S2), despite the latter putting a great weight on differences in species relative abundances. The only notable difference between the results obtained from the different distance/dissimilarity measures was the absence of significant grazing and fertilizer $\times$ grazing effects when only presence-absence data were considered $(P=0.190$; Table S1). The fertilizer $\times$ grazing interaction was also marginally nonsignificant $(P=0.059)$ when the MG2 distance was used (Table S2).

\section{DISCUSSION}

Both vegetation sampling methods gave qualitatively similar results, although the VR method gave greater estimates of the abundance of lupin, fescue tussock, and tall oat-grass, and gave slightly lower estimates of the abundance of mouse-ear hawkweed and zig-zag clover, relative to the PC method. Despite these differences, we found that the effect of sampling method on observed vegetation composition was consistent among fertilizer and grazing treatments. This suggests that both sampling methods were equally good at detecting management effects on vegetation composition in these grasslands. This is reinforced by the fact that modifying the relative importance given to changes in presence-absence or relative abundances by 


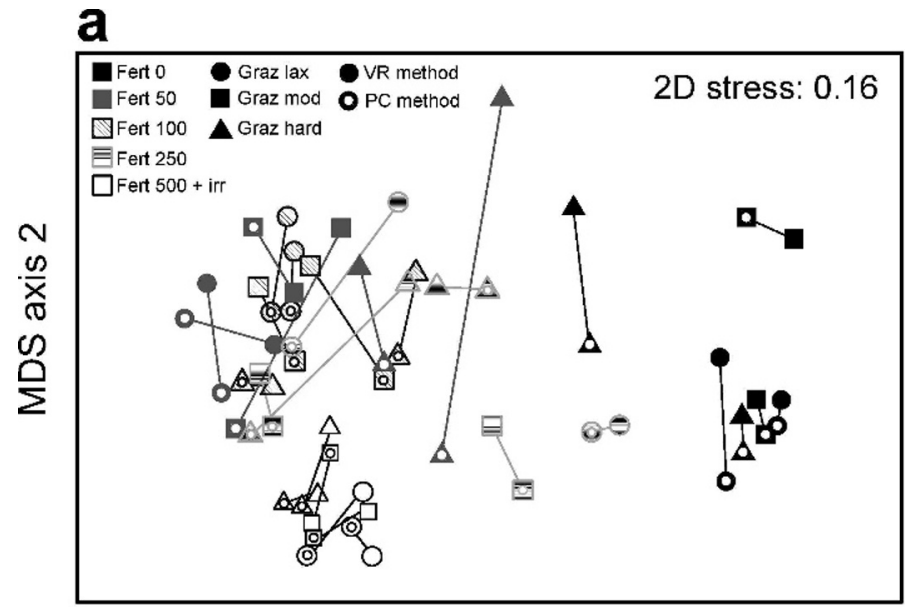

MDS axis 1

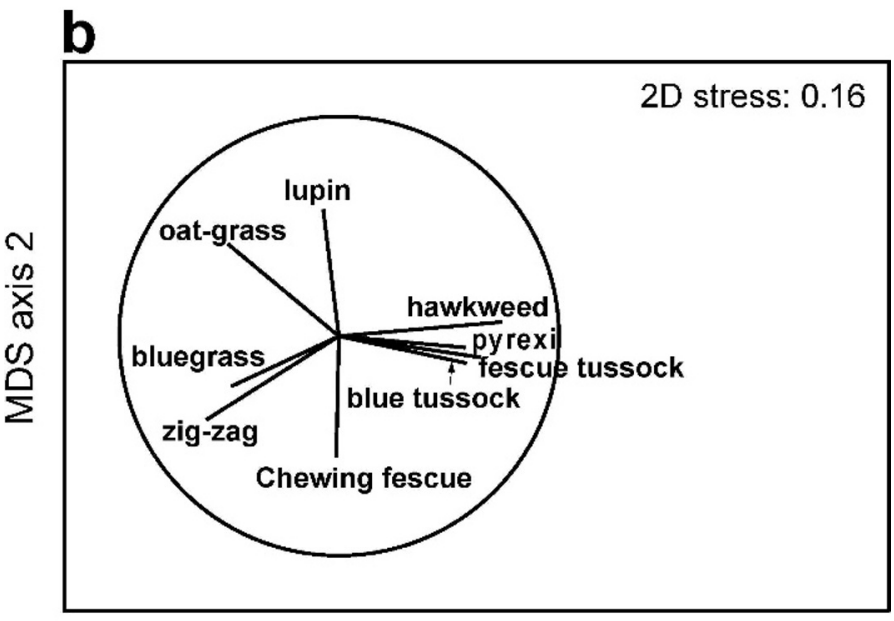

MDS axis 1

Figure 2. Nonmetric multidimensional scaling (MDS) of the vegetation composition data, showing (a) subplots and (b) species. The ModifiedGower distance with base 10 (Anderson et al. 2006) was used. In panel $\mathbf{b}$, the length and direction of each vector (species) indicates the strength and sign of the correlation between the two MDS axes. Only species showing a Pearson correlation $r>0.5$ with any of the two MDS axes are shown. Black symbols $=0 \mathrm{~kg}$ superphosphate $\cdot \mathrm{ha}^{-1} \cdot \mathrm{yr}^{-1}$; Dark gray symbols $\left(45^{\circ}\right.$ hatched $)=50 \mathrm{~kg}$ superphosphate $\cdot \mathrm{ha}^{-1} \cdot \mathrm{yr}^{-1}$; gray symbols $=100 \mathrm{~kg}$ superphosphate $\cdot \mathrm{ha}^{-1} \cdot \mathrm{yr}^{-1}$; light gray symbols (horizontally hatched) $=250 \mathrm{~kg}$ superphosphate $\cdot$ ha $^{-1} \cdot \mathrm{yr}^{-1}$; white symbols $=500 \mathrm{~kg}$ superphosphate $\cdot \mathrm{ha}^{-1} \cdot \mathrm{yr}^{-1}+$ irrigation. Circles = lax grazing; squares = moderate grazing; triangles = hard grazing. Symbols linked by lines indicate the same subplot sampled under the percent cover (PC) method (white dots) or the visual ranking (VR) method (no dots). pyrexi $=$ Pyrranthera exigua (Kirk) Zotov.

using different distance measures had little effect on our results. Even though sampling method did influence the observed vegetation composition, this effect was an order of magnitude smaller than the main fertilizer effect. In addition, grazing effects were still detected irrespective of sampling method, despite grazing having subtler effects on the observed vegetation composition than the sampling method itself.

Differences between sampling methods were primarily driven by lupin, a tall species relative to the other species. The PC
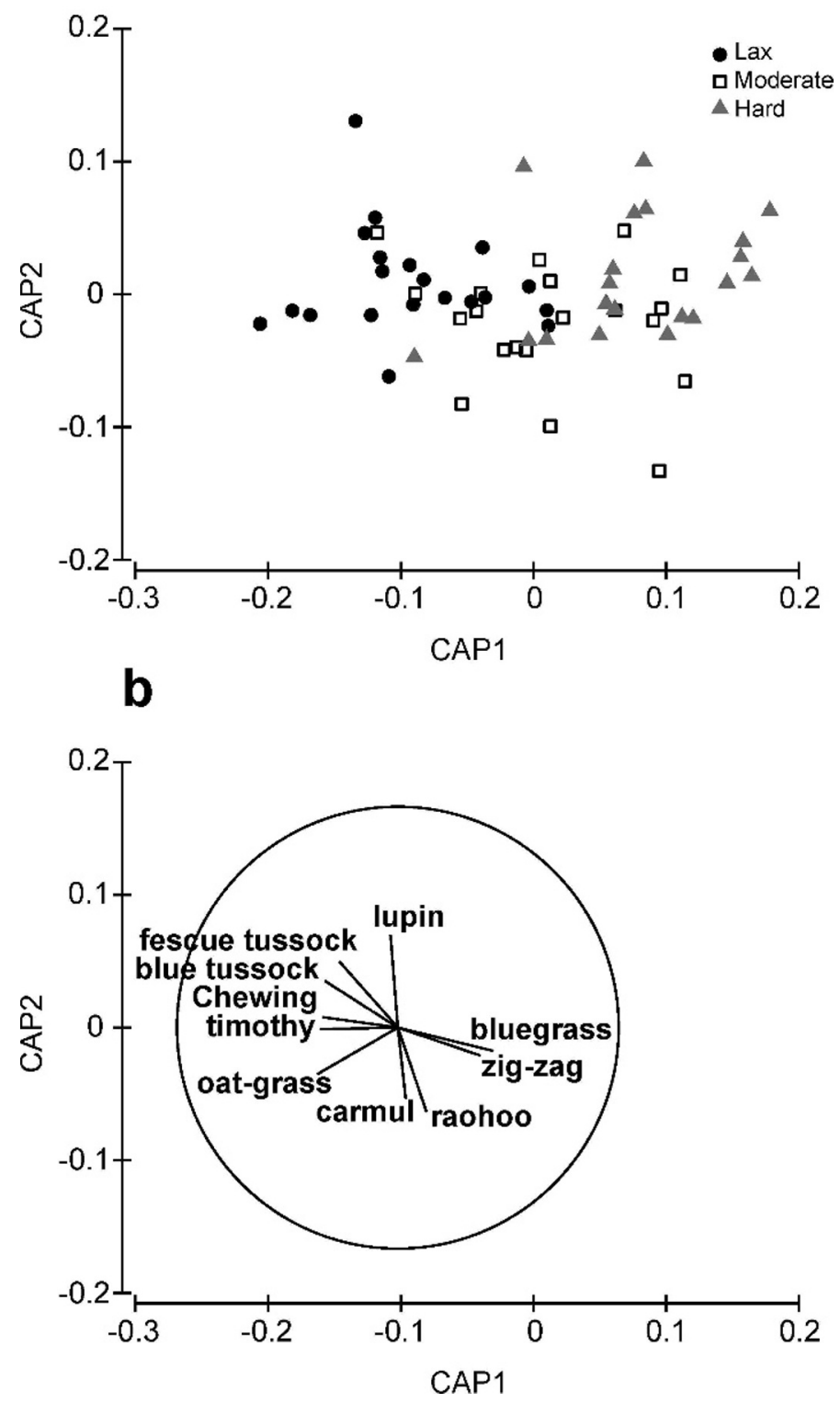

Figure 3. Canonical analysis of principal coordinates (CAP) highlighting the differences in vegetation composition (Modified Gower distance base 10) among (a) subplots under different grazing intensities. (b) Vectors represent the species showing a Pearson correlation $r>0.3$ with any of the two CAP axes. carmul = Carex muelleri Petrie; raohoo $=$ Raoulia hookeri Allan.

method gave lower abundance estimates for this species compared to the VR method. It is also notable that the other two species, which were underestimated by the PC method (tall oat-grass and fescue tussock; see Fig. 1), were also tall, whereas species that were overestimated by the PC method (zig-zag clover and mouse-ear hawkweed, see Fig. 1) were relatively small in size. These differences between the two methods are likely due to the fact that the VR method uses standing biomass as the measure of "abundance" (Scott 1989), whereas the PC method uses ground projection of canopy cover. Clearly, in communities where species differ greatly in height or life form (e.g., open shrublands), large differences between results 
obtained with the VR and PC methods may be expected strictly because of the respective focus of each method on different measures of "abundance." However, in our case all plots were dominated by herbaceous vegetation, and differences between the two methods were not large enough to influence their ability to detect changes in vegetation composition.

In this study, the two vegetation sampling methods compared were both based on visual estimation, either of species standing biomass or of canopy cover. Recently, ground-based or aerial digital imagery have been proposed as more rapid and cost-effective alternatives to visual estimation of vegetation cover in rangelands (Seefeldt and Booth 2006). However, these new digital technologies can currently be used only to measure overall plant cover (Seefeldt and Booth 2006) or to measure the relative cover of different plant life forms (e.g., grasses, forbs, and shrubs; Luscier et al. 2006), but not individual species. The emerging field of "airborne spectranomics" may eventually allow distinction at the species level from aerial or satellite images (Asner and Martin 2009), but this is still far from being available as a rangeland monitoring tool. Until then, groundbased estimation of plant species abundances remains the best available tool for monitoring changes in rangeland vegetation composition following the adoption of new management strategies. Direct measurement of plant biomass by species has been widely used in grassland/rangeland assessment and arguably remains the most accurate method, but faster and more cost-efficient visual estimation methods often need to be used. Of the two visual methods compared here, the VR method was as good as the PC method at detecting changes in vegetation composition following rangeland development, yet was about an order of magnitude faster (i.e., $\sim 3 \mathrm{hr}$ for VR vs. $\sim 30 \mathrm{hr}$ for PC).

Although the primary interest of this study was to test for differences in observed vegetation composition under different sampling methods, our results identified a strong effect of fertilizer and much a smaller, but still significant, effect of grazing intensity. Subplots receiving no fertilizer were characterized by a greater abundance of mouse-ear hawkeweed, blue tussock, fescue tussock, and Pyrranthera exigua (Kirk) Zotov compared to fertilized plots. These species are characteristic of the vegetation prior to establishment of the experiment (Scott 1999). Within fertilized plots, those receiving $500 \mathrm{~kg} \cdot \mathrm{ha}^{-1} \cdot \mathrm{yr}^{-1}$ of superphosphate and irrigation contained more Chewing's fescue and less lupin (Fig. 1). While grazing intensity has been shown to cause strong threshold changes in vegetation composition of Mongolian rangelands (Sasaki et al. 2008), our results show instead a strong threshold response in vegetation composition following the application of superphosphate, but a much smaller effect of grazing intensity.

With regard to grazing intensity, lax grazing favored timothy, Chewing's fescue, and tall oat-grass, while hard grazing favored zig-zag clover and Kentucky bluegrass. These results are consistent with earlier findings (Scott 2007). One of our future research goals with the "Graze $\times$ fert" trial is to use functional characteristics of the species (e.g., leaf morphological and chemical leaf traits) in order to gain a more mechanistic understanding of species' response to both fertilizer and grazing intensity.
We purposefully excluded uncommon species from our analyses because the VR method aimed at characterizing vegetation composition by ranking the 10 most abundant species only in each subplot. Monitoring native and overall species richness in rangelands is important from a conservation perspective (e.g., Symstad et al. 2008; Godínez-Alvarez et al. 2009), especially because species richness has been shown to vary under changing management in New Zealand rangelands (Norton et al. 2006). Nevertheless, vegetation composition, as expressed by the dominant species, is still useful for most agronomic applications (e.g., Scott 2007). Moreover, as predicted by the mass-ratio hypothesis (Grime 1998), vegetation effects on ecosystem biogeochemical processes should be primarily driven by the most abundant species (Mokany et al. 2008), such that excluding rare species from the analysis would not alter our ability to assess vegetation feedbacks on ecosystem-level processes.

Most comparisons of vegetation sampling methods in rangelands have focused on species richness (e.g., West and Reese 1991; Stohlgren et al. 1998; Godínez-Alvarez et al. 2009) and/or the cover of individual species or functional groups (Prosser et al. 2003; Symstad et al. 2008), but none to our knowledge has focused on changes in vegetation composition as we have done here. In this study, we have used the PC and the VR methods to sample only the most abundant species in each plot, but both methods could be extended to more detailed biodiversity surveys. However, if the focus is to detect main changes in vegetation composition from the perspectives of rangeland agronomy or rangeland ecological functions, our results show that the VR is as good as the PC method, despite the latter being a more field-intensive method using repeated subsampling.

\section{IMPLICATIONS}

The purpose of this study was to compare a rapid VR vegetation sampling method (Scott 1989) to a more fieldintensive PC method based on repeated subsampling with many quadrats. Both methods were equally good at detecting changes in vegetation composition under different fertilizer and grazing intensity regimes. The VR method gave higher abundance estimates for lupin relative to the PC method, most likely because the measure of "abundance" differed between methods (standing biomass for VR, and canopy cover for PC) and because of the greater height of lupin relative to other species. However, differences between methods on observed vegetation composition were very small compared to the main effect of fertilizer. The much greater efficiency of the VR method compared to the PC method (i.e., about 10 times faster in the present study) supports the use of the VR method as a rapid yet powerful method for detecting changes in vegetation composition following rangeland development, at least in grasslands.

\section{ACKNOWLEDGMENTS}

We wish to thank M. J. Anderson for advice on statistical analyses, P. Fortier for help with field work, A. Simpson for the use of stock, and G. Peralta for translating the Abstract into Spanish. 


\section{LITERATURE CITED}

Anderson, M. J., K. E. Ellingsen, and B. H. McArdle. 2006. Multivariate dispersion as a measure of beta diversity. Ecology Letters 9:683-693.

Anderson, M. J., R. N. Gorley, and R. Clatke. 2008. PeRMAnova+ for PRimer: guide to software and statistical methods. Plymouth, United Kingdom: PRIMER-E. $214 p$

Anderson, M. J., AND J. Robinson. 2003. Generalised discriminant analysis based on distances. Australian and New Zealand Journal of Statistics 45:301-318.

Anderson, M. J., And T. J. Willis. 2003. Canonical analysis of principal coordinates: a useful method of constrained ordination for ecology. Ecology 84:511-525.

Asner, G. P., and R. E. Martin. 2009. Airborne spectranomics: mapping canopy chemical and taxonomic diversity in tropical forests. Frontiers in Ecology and the Environment 7:269-276.

Clarke, R., and R. N. Gorley. 2006. PRIMER v6: user manual/tutorial. Plymouth, United Kingdom: PRIMER-E. $91 \mathrm{p}$.

Friedel, M., and V. Chewings. 1988. Comparison of crown cover estimates for woody vegetation in arid rangelands. Australian Journal of Ecology 13:463-468.

Godínez-Alvarez, H., J. Herrick, M. Mattocks, D. Toledo, and J. Van Zee. 2009. Comparison of three vegetation monitoring methods: their relative utility for ecological assessment and monitoring. Ecological Indicators 9:1001-1008.

Gotell, N. J., AND A. M. ElLIson. 2004. A primer of ecological statistics. Sunderland, MA, USA: Sinauer Associates. $479 \mathrm{p}$.

GRIME, J. P. 1998. Benefits of plant diversity to ecosystems: immediate, filter and founder effects. Journal of Ecology 86:902-910.

HewITT, A. E. 1998. New Zealand soil classification. Lincoln, New Zealand: Manaaki Whenua Press. 133 p.

Hunter, G. G. 1991. The distribution of hawkweeds (Hieracium spp.) in the South Island, indicating problem status. Tussock Grasslands and Mountain Lands Institute Review 48:21-31.

KRUSKAL, J. B. 1964. Multidimensional scaling by optimizing goodness of fit to a nonmetric hypothesis. Psychometrika 29:1-27.

Legendre, P., and L. Legendre. 1998. Numerical ecology. Amsterdam, the Netherlands: Elsevier Science. $853 \mathrm{p}$.

Linklater, W., and E. Cameron. 2000. Tests for cooperative behaviour between stallions. Animal Behaviour 60:731-743.

LinkLater, W., and E. Cameron. 2009. Social dispersal but with philopatry reveals incest avoidance in a polygynous ungulate. Animal Behaviour 77:1085-1093.

Luscier, J. D., W. L. Thompson, J. M. Wilson, B. E. Gorham, and L. D. Dragut. 2006. Using digital photographs and object-based image analysis to estimate percent ground cover in vegetation plots. Frontiers in Ecology and the Environment 4:408-413.

McArdle, B. H., and M. J. Anderson. 2001. Fitting multivariate models to community data: a comment on distance-based redundancy analysis. Ecology 82:290-297.

McGLone, M. S. 2001. The origin of native grasslands of southeastern South Island in relation to pre-human woody ecosystems. New Zealand Journal of Ecology 25:1-15.

Meentemeyer, R., And A. Moody. 2000. Rapid sampling of plant species composition for assessing vegetation patterns in rugged terrain. Landscape Ecology 15:697-711
Mokany, K., J. Ash, and S. RoxbuRgh. 2008. Functional identity is more important than diversity in influencing ecosystem processes in a temperate native grassland. Journal of Ecology 96:884-893.

Mueller-Dombois, D., and H. Ellenberg. 2003. Aims and methods of vegetation ecology. Caldwell, NJ, USA: Blackburn Press. 547 p.

Norton, D. A., P. R. Espie, W. Murray, and J. Murray. 2006. Influence of pastoral management on plant biodiversity in a depleted short tussock grassland, Mackenzie Basin. New Zealand Journal of Ecology 30:335-344.

Oksanen, J., R. Kindt, P. Legendre, B. O'Hara, G. L. Simpson, P. Solymos, M. H. H. Stevens, and H. WaGner. 2010. vegan: community ecology package. $\mathrm{R}$ package version 1-17.0. Vienna, Austria: The Comprehensive $\mathrm{R}$ Archive Network (CRAN). Available at: http://cran.r-project.org/. Accessed 29 July 2010.

Peres-Neto, P. R., and D. A. Jackson. 2001. How well do multivariate data sets match? The advantages of a Procrustean superimposition approach over the Mantel test. Oecologia 129:169-178.

Prosser, C., K. Skinner, and K. Sedivec. 2003. Comparison of 2 techniques for monitoring vegetation on military lands. Journal of Range Management 56:446-454.

Sasaki, T., T. Okayasu, U. Jamsran, and K. Takeuchi. 2008. Threshold changes in vegetation along a grazing gradient in Mongolian rangelands. Journal of Ecology 96:145-154

ScotT, D. 1985. Hawkweeds in run country. Tussock Grasslands and Mountain Lands Institute Review 42:33-48.

ScotT, D. 1989. Description of vegetation using visual ranking of species. New Zealand Journal of Ecology 12:77-88.

ScotT, D. 1999. Sustainability of New Zealand high-country pastures under contrasting development inputs. 1. Site, and shoot nutrients. New Zealand Journal of Agricultural Research 42:365-383.

ScotT, D. 2001. Sustainability of New Zealand high-country pastures under contrasting development inputs. 7. Environmental gradients, plant species selection, and diversity. New Zealand Journal of Agricultural Research 44:59-90.

ScotT, D. 2007. Sustainability of high-country pastures under contrasting development inputs. 9. Vegetation dynamics. New Zealand Journal of Agricultural Research 50:396-406.

Seefeldt, S., And D. Booth. 2006. Measuring plant cover in sagebrush steppe rangelands: a comparison of methods. Environmental Management 37: 703-711.

ShePARD, R. N. 1962. The analysis of proximities: multidimensional scaling with an unknown distance function, I. Psychometrika 27:125-140.

Stohlgren, T. J., K. A. Bull, and Y. Otsuki. 1998. Comparison of rangeland vegetation sampling techniques in the Central Grasslands. Journal of Range Management 51:164-172.

Symstad, A. J., C. L. Wienk, and A. D. Thorstenson. 2008. Precision, repeatability, and efficiency of two canopy-cover estimate methods in Northern Great Plains vegetation. Rangeland Ecology and Management 61:419-429.

't Mannetje, L., and K. P. Haydock. 1963. The dry-weight rank method for the botanical analysis of pastures. Journal of the British Grassland Society 18:268-275.

Warton, D. I., I. J. Wright, D. S. Falster, and M. Westoby. 2006. Bivariate line-fitting methods for allometry. Biological Reviews 81:259-291.

West, N., And G. Reese. 1991. Comparison of some methods for collecting and analyzing data on aboveground net production and diversity of herbaceous vegetation in a northern Utah subalpine context. Vegetatio 96:145-163. 